\title{
"Allergic Bronchopulmonary Aspergillosis: Radiological and Microbiological Profile of Patients Presented in an Outpatient Pulmonary Clinic of a Developing Country".
}

Nousheen lqbal ( $\square$ nousheen.iqbal@aku.edu )

Aga Khan University Hospital https://orcid.org/0000-0001-5026-9874

Muhammad Irfan

Aga Khan University Hospital

Mustafa bin Ali Zuabairi

dow university of health and sciences

Maaha Ayub

Aga Khan University Medical College Pakistan

Safia Awan

Aga Khan University

Kausar Jabeen

Aga Khan University Hospital

Ali Zuabairi

Aga Khan University Hospital

Keywords:

Posted Date: November 2nd, 2020

DOI: https://doi.org/10.21203/rs.3.rs-99498/v1

License: (c) (i) This work is licensed under a Creative Commons Attribution 4.0 International License.

Read Full License 


\section{Abstract}

The authors have requested that this preprint be removed from Research Square. 